\title{
Using the Awareness, Desire, Knowledge, Ability, Reinforcement Model to build a shared governance culture
}

\author{
Mary L. Shepherd ${ }^{1}$, Mary L. Harris ${ }^{1}$, Heather Chung ${ }^{2}$, Elizabeth M. Himes ${ }^{3}$ \\ 1. Nursing Strategy and Operations, Houston Methodist Hospital, Houston, Texas, USA. 2. Behavioral Health Transitions in \\ Care, Houston Methodist Hospital, Houston, Texas, USA. 3. Nursing Operations, Houston Methodist Hospital, Houston, \\ Texas, USA.
}

Correspondence: Mary Shepherd. Address: 6565 Fannin, MGJ 6-023, Houston, Texas 77030, USA.

Email: MLShepherd@houstonmethodist.org

Received: February 21, 2014

DOI : $10.5430 /$ jnep.v4n6p90
Accepted: March 28, $2014 \quad$ Online Published: April 29, 2014

URL: http://dx.doi.org/10.5430/jnep.v4n6p90

\section{Abstract}

A legacy of shared governance experience at Houston Methodist Hospital (HMH) has yielded many lessons regarding the leadership support, staff engagement, structures, and processes essential to successful implementation of a shared governance model. Shared governance is described as an effective vehicle for optimizing care delivery. Nurses play an integral role in improving the quality of care and must be competent and have access to tools, education, and resources that increase their capacity to think creatively when designing and optimizing care delivery. Creating a learning environment that instills competency and confidence enables nurses to provide care within their full scope of practice. In our experience, it was imperative that the Board of Directors and senior management understood the concepts and benefits of shared governance to receive buy-in. With their approval, the next challenge was obtaining support from nursing leaders and shared governance chairs. Implementation strategies included adaptation of the Awareness, Desire, Knowledge, Ability, Reinforcement (ADKAR) Model, identification of shared governance core competencies, and education of nursing leaders and governance chairs through ongoing educational modalities. Education on shared governance principles, concepts, competencies, roles, council structure, and processes in addition to a clinical competency focus were vital to the implementation and integration of shared governance and set the pace for success. Shared governance is a cultural change that promotes bedside clinicians' ownership of practice and positively impacts patients, families, staff, and organizational outcomes. Over a 13-year period, the shared governance structure matured, which resulted in higher registered nurse satisfaction, improved registered nurse retention, and patient outcomes that outperformed national benchmarks.

\section{Key words}

Shared governance, Empowerment, Autonomy, Control over practice, Competency, Awareness, Desire, Knowledge, Ability, Reinforcement (ADKAR) Model

\section{Background and significance}

In 2000, the nursing leadership at Houston Methodist Hospital (HMH) made the decision to pursue Magnet recognition by the American Nurses Credentialing Center (ANCC). The Magnet Recognition Program provides a framework for organizations to transform the environment, thus enabling the staff and patient care to flourish. Nursing's vision was 
"Leading the world of nursing in an innovative and collaborative environment of excellence in patient care, education, and research.” Shared governance was an essential component of this and a requirement of the Magnet Program.

HMH resides in the Texas Medical Center, where it competes with several other academic hospitals, thus making it a priority to focus not only on the quality of patient care, but also the satisfaction and retention of nurses. Nursing leadership quickly moved to adopt a new strategy that would enable bedside clinicians to function autonomously and exert greater control over their practice. Shared governance was the vehicle chosen to restructure the environment and drive a culture of empowerment and excellence in patient care, while also improving nurse satisfaction and retention.

A compounding and compelling factor for shifting the hospital's practice model was the dynamic health care environment, increasing competition for market share, declining reimbursement, increasing complexity of patient care, and demand for higher quality and greater patient safety and satisfaction. Over the past decade, health care reform in the private and public sectors has sparked a new period of transformation that has disrupted the current way that nurses provide care. This revolutionized state has prompted nursing leaders to prioritize the outcomes associated with care and to create new strategies that will place unprecedented pressure on health care providers to achieve better outcomes as health care coverage expands to more than 32 million Americans. With the passage of the Affordable Care Act (ACA) in 2010, care delivery and financing systems have experienced immense change that will continue to accelerate in 2014. Implementation of the ACA has resulted in greater alignment of goals to enhance care coordination and improve patient transitions across the care continuum. The demand for nurses to be involved in the community setting, to focus on prevention, and to coordinate treatment and chronic care collaboratively with the inter-professional team and with the use of technology will grow ${ }^{[1]}$. The new model of care has driven hospitals to move away from contemporary fee-for-service and to switch to a value-based model of care. Nurses are now held accountable for patient treatment outcomes, which are directly linked to a hospital's federal reimbursement.

HMH has taken a proactive approach to ensure that the nursing workforce is sufficiently positioned to respond and has the capacity to ensure quality and safe delivery of care to patients. Ongoing competency training and change in patient conditions classes are offered regularly to ensure that nurses have the didactic and clinical skills needed to deliver care based on bundled variables. For example, when a patient has a Foley catheter, a nurse has eight variables that must be assessed to ensure that a patient does not acquire a hospital infection, which would inhibit reimbursement. The class on changing patient conditions is aimed at sharpening critical thinking and synthesis skills, thus enabling nurses to recognize patients who need to be rescued owing to a change in clinical condition.

This article describes strategies, such as the ADKAR Model used, to build a shared governance culture to prepare bedside clinicians to own their practice and patient outcomes.

\subsection{Literature review}

The Magnet Recognition Program requires that organizations demonstrate excellence in three key areas: patient satisfaction, clinical performance, and nursing satisfaction. The patient care delivery system is the core of the program. Within this framework, nurses are expected to practice autonomously to meet the unique needs of the patient and family ${ }^{[2]}$.

Shared governance provides a structure with which to organize the delivery of care in order to improve patient and staff satisfaction and clinical outcomes ${ }^{[3]}$. The catalyst for achieving these outcomes is staff engagement, competency, autonomy, and accountability for practice. Leadership support and facilitation of staff autonomy are congruent with increased nursing performance and improved patient outcomes ${ }^{[4]}$. In a letter to the editor of the Journal of Nursing Administration, Tim Porter-O'Grady ${ }^{[5]}$ wrote, "I submit that without a shared decision-making structural framework, the processes of excellence measured by the Magnet program would have no way to be sustained.”

Professional nurse autonomy and control over practice are concepts associated with a therapeutic work environment, job satisfaction, nurse retention ${ }^{[6]}$, and effective patient care and outcomes ${ }^{[7]}$. Autonomy has been described as having the 
authority to make independent decisions and to take actions in accordance with one's discretion and professional knowledge ${ }^{[8]}$. Muñiz Castillo ${ }^{[9]}$ expanded this definition by addressing not only a person's capacity or freedom to choose, but also a person's capacity to achieve his or her goals. She referred to autonomy as a human need that is intrinsically important to a person's development and is promoted when a person perceives that he or she has the freedom to choose. To function autonomously, however, nurses must develop the expertise that allows them to exercise sound clinical judgment and exert control over their practice. Certain satisfiers must be met, for example, resources must be provided and autonomy supported to achieve an adequate level of competency ${ }^{[9]}$. In addition, autonomy is predicated on certain conditions being present, such as freedom from coercion, opportunity for thoughtful reflection, and having sufficient information and knowledge ${ }^{[10,11]}$.

Only a limited number of studies have examined the relationship between shared governance and empowerment in nursing. Barden et al.'s ${ }^{[12]}$ study examined the relationship between perception of shared governance and empowerment among nurses who work in a professional governance structure in a hospital setting. The theoretical framework for their study was based on Kanter's ${ }^{[13]}$ structural theory of empowerment, which suggests that the organizational structures of information, support, resources, and opportunity lead to work effectiveness and empowerment. Barden et al. found a significant relationship between shared governance and empowerment; as shared governance increased, so did empowerment. In his book, Drive, Pink ${ }^{[14]}$ examined what motivates people to do what they do. Pink suggested that modern-day work (including nursing) is more heuristic, right-brained, and creative; involves problem-solving and critical thinking; and is focused on long-term mastery. Instead of relying on the organization to empower the worker, the organization supports the worker's autonomy, mastery, and purpose. Autonomy leads to engagement as leaders create conditions for people to do their best work. According to Pink, autonomy over task, time, technique, and team leads to innovation and growth. Examples of autonomy in a shared governance environment include self-scheduling and determining work methods, procedures, and processes and the criteria for setting and meeting goals. Autonomy also includes clinical autonomy, in which nurses make decisions within policies and rules about individual patients ${ }^{[15]}$.

Mastery is described by Dweck ${ }^{[16]}$ as a mindset that views intelligence as something one develops. Learning goals leads to mastery and knowledge application as a person desires to get better and better at something that matters, whereas assigned individual performance goals may hinder application of knowledge because such goals may focus on what is easily attainable. Learning goals lead to engagement, whereas assigned performance goals may only lead to compliance. Through shared governance, engagement of staff takes place to solve complex problems, both individually and as a team; shared governance also increases the propensity to make progress and provides a mechanism for feedback on ways to improve. Engaged employees are focused on long-term mastery, which involves hard work, a desire to continually improve, and the nature to persevere in the face of difficult circumstances.

People often have higher goals than the ones they're assigned. Pink ${ }^{[14]}$ described three steps that leaders can take to give up control:

1) Involve staff in goal-setting. Involving staff in goal-setting leads to increased staff engagement.

2) Use non-controlling language. Promote employee engagement by using phrases such as "think about it," "consider it," "what would happen if," and "have you ever thought about...." Using language to promote compliance may yield short-term results; however, just a simple change in the way that a leader answers an employee can lead to the employee's engagement and a solution that is better than the one the leader had in mind.

3) Hold office hours. Create an environment that facilitates the staff talking with the leader about anything that is on their minds. Be available and aware of the impact that nonverbal communication relays to the staff.

At $\mathrm{HMH}$, a transformational leadership style is a consistent trait of most leaders. This trait was integral in gaining momentum during the early implementation stages when staff awareness was being raised regarding the importance of 
embracing the Magnet Recognition Program and shared governance as vehicles to drive and own superior outcomes associated with the delivery of care. This leadership style moved the staff beyond their own self-interests to a greater sense of purpose that went beyond the final ADKAR stage of reward to one of understanding the effort at hand and understanding the benefits to both the staff at large and the organization.

Hooper and Potter ${ }^{[17]}$ extended the notion that transformational leadership includes seven key competencies that are characteristic of "transcendent leaders," as follows: setting direction, setting example, communicating and aligning, bringing out the best in people, leading as a change agent, and making decisions in the face of crisis and ambiguity. Leaders who are able to engage the emotional support of their followers will effectively transcend change. Transformational leadership is the recognized style in which the leaders in this organization take actions and emulate behaviors to increase staff awareness of what is right and important. HMH leaders raise the staff's motivational maturity and encourage them to go beyond their own self-interests for the good of the group, organization, or society. As change agents, these leaders communicate with the staff to provide them with a sense of purpose that goes beyond the simple exchange of rewards for their efforts. They also optimize the development of competencies that transcend personal gain and promote the maturity of ability, motivation, attitudes, and values ${ }^{[17]}$.

Shared governance offers a venue that instills a shared purpose and cause larger than the individuals themselves. This vehicle brings people and resources together to create value and purpose that no single individual can produce alone. In a Magnet environment, ANCC sets the expectation that Magnet hospitals produce evidence not only of what they have done but also of the difference they have made.

\subsection{Challenges}

Before implementing a shared governance model, there must be an understanding of where the organization stands in terms of its knowledge and willingness to begin this journey. A number of factors influence the readiness of an organization and nursing staff to implement shared governance, for example, knowledge of shared governance concepts, the managers' understanding and acceptance of the change and their participative management style, and willingness of both the managers and the staff to maintain an open relationship in which controversial issues that emerge are addressed ${ }^{[18]}$. Other factors that warrant consideration are staff tenure, staffing mix, group dynamics, driving forces (such as what managers and staff value), the existence of a well-defined patient care delivery system, and recognition and incentives for a job well done. Understanding the culture and the staff's readiness for change are essential in determining the timing of implementation ${ }^{[19]}$.

As with any change, resistance may be precipitated by fear of the unknown and potentially a perceived threat to the role of individuals. Shifting the role of managers from one of authority and control to one of engagement, facilitation, and coaching came easy for some managers at HMH who were confident and comfortable with their role. This shift was a more difficult transition for others. First the managers had to understand the vision for driving this practice change, overcome any psychological barriers associated with relinquishing authority and control, have an opportunity to collaborate with colleagues who had successfully implemented this model, and then acquire in-depth knowledge and the skills to move forward. Relinquishing control is counter to one's nature and creates a tendency to revert to controlling behaviors that are perceived to be safe and less risky. Changing this behavior thus required extensive coaching and reinforcement to secure buy-in, secure commitment, and build enthusiasm to embrace this change.

Changing the behavior and willingness of the staff to adapt to an expanded role in which they designed their practice and owned outcomes associated with their care delivery system and other unit performance factors (such as driving quality assurance, performance improvement, process redesign, and resource management) also required extensive education, coaching, and communication. Figure 1 lists these unit performance factors. At the onset, the staff verbalized that it was too much work and that they did not have the time or the skills to participate in shared governance. This signaled a lack of understanding of shared governance concepts and the benefits and possibly an issue with the allocation of time. The staff 
needed to be confident that they would be empowered to make decisions and have the time and resources needed to get things done. Ultimately, the managers had to trust that the staff could (competence) and would do what they said. Conversely, the staff had to trust that the managers believed in their ability to succeed and would support them in their new role.

Figure 1. Houston Methodist Shared Governance Unit Performance Factors

Shared Governance Unit Performance Factors are structures, processes, and systems that impact nursing's performance and the outcomes associated with the care delivery system. In a shared governance environment, optimal outcomes may be achieved by empowering bedside clinicians to make decisions that influence and drive these factors.
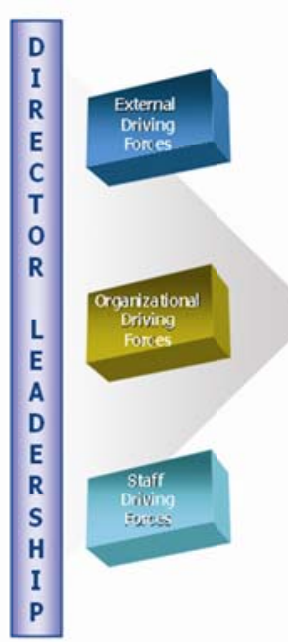

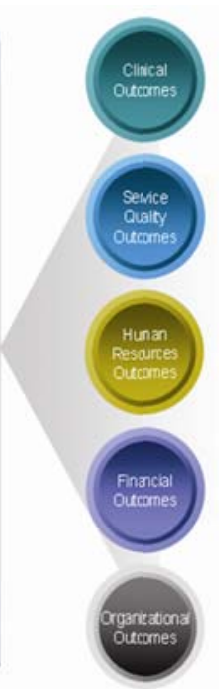

Prior to implementing shared governance, the nursing leadership administered a baseline survey to determine the staff's knowledge of shared governance concepts, perceived barriers, and their willingness to implement shared governance. Several key variables associated with a shared governance environment were identified through a literature review that served as the basis for a questionnaire that was distributed electronically to 1119 nurses throughout the organization before the implementation process. In 2000, HMH had just begun its journey toward Magnet designation. The low response rate (63 nurses, or $6 \%$ of the population) may have indicated a lack of knowledge of the value of shared governance or a lack of staff engagement, which thus reinforced the need to move forward with this practice model. The nurses who did respond identified several opportunities. These results were evident in the verbal feedback that was initially received from the staff. The results of this baseline shared governance survey are summarized in Table 1.

Table 1. Shared governance baseline survey results: percentage of nurses who responded "Yes" (2000)

\begin{tabular}{ll}
\hline Survey Question & Percentage \\
\hline Staff buy-in/ownership & $53 \%$ \\
Structure for shared decision-making (shared governance) in place & $41 \%$ \\
Knowledge of shared governance role & $26 \%$ \\
Knowledge of how to form a council & $40 \%$ \\
\hline
\end{tabular}

Implementation of the structure and processes that supported the governance model was relatively straightforward. Each nursing unit was provided with a blueprint and a coach who guided the composition. Obtaining buy-in and ownership to alter traditional norms and to integrate a fully operating and effective practice model required persistence and a comprehensive multi-pronged approach that encompassed the knowledge, skills, and behavior of the managers and staff.

\section{Methods}

Change management requires a structured step-by-step approach that enables a transition from a current state to a desired future state. Inherent in this process is preparing for the change and managing and reinforcing the change. Moving from a traditional hierarchy to one of shared governance constituted a major cultural shift for $\mathrm{HMH}$, warranting the management 
of both the tactical and the human side of change. The people side of change is frequently cited as contributing to failure ${ }^{[20]}$, thus making it a priority to focus on this aspect of the change process.

Numerous models can be used to change a culture. Prosci Inc., a business process re-engineering company, developed ADKAR, which is a goal-oriented, five-step management model that gives organizations a framework for change initiatives with an emphasis on the people side of change. The elements of this model are summarized in Table 2.

Table 2. ADKAR Change Management Model*

Awareness of why the change is needed sets the stage for communicating the vision for the future state and other key messages about the change, such as the business reasons, scope of the change, who is impacted, what will change, and the timeline. During this phase, input should be sought.

Desire to particiapte and support the change is influenced by numerous factors, for example, discontent with the current state, impending negative consequences, previous experience with change or personal impact, and intrinsic motivators, such as career advancement or a chance to acquire more power and enhanced compensation and job security. During this phase, listening and understanding concerns and misunderstandings regarding the change are essential and present an opportunity to focus on the benefits, while eliminating barriers and instilling optimism in the change.

Knowledge on how to change enables staff to undertand what the change is and how it will look and impact their role. Education must address the knowledge, skills, and behaviors needed to function in the new environment and mechanisms for addressing problems during the change process. Training and education may be provided through a combination of vehicles, for example, classroom instruction, workshops, retreats, on-line modules, and by role models. Access to information enhances the learning process.

Ability to implement required skills and behaviors focuses on the application of new skills, processes and behaviors that have been learned and potential implementation barriers. During this phase, the staff need time to practice, while learning from a role model or coach who ensures that they have an understanding of their new role and responsibilities, process and system changes, and new technology that may support their work and team dynamics. Managers are pivitol in eliminating these barriers or for seeking additional expertise to help eliminate obstacles.

Reinforcement to sustain the change revolves largely around employee recognition and rewards for a job well done. This can range from personal recognition, celebrations, compensation, and benefits to having the right equipment and tools and good relationships with managers and co-workers.

*Source: Summarized from ADKAR: A Model for Change in Business, Government and Our Community ${ }^{\text {[20] }}$

In looking back retrospectively, HMH’s implementation plan was aligned with the five steps of the ADKAR Model. The baseline data collected to assess the staff's knowledge of shared governance concepts, perceived barriers, and willingness to implement shared governance identified gaps that guided the planning of various implementation strategies and tactics. An internal design team with shared governance knowledge and experience was convened to plan and oversee the implementation phase and reinforce the new structure, processes, and roles by serving as a resource to nursing leaders and staff on each nursing unit as the plan moved forward.

The design team reviewed models of nursing governance that would facilitate the work of nursing. Working collaboratively with HMH's chief nurse and other nursing executives, a councilor structure aligned with nursing's key accountabilities (i.e., practice, quality, education, and evidenced-based practice) was selected for implementation at the house-wide and unit levels. The entire governance structure reported to the Nursing Leadership Council chaired by the Chief Nurse Executive and composed of nursing executives, the house-wide chairs, representatives from each clinical specialty, and members of the design team. In addition, the team determined the scope of the change, defined people changes and competencies, and identified new structures, processes, information and technology needs, communication and training plans, timelines, and resources to coach and actively support this transition, which spanned several months with ongoing support. Table 3 outlines the implementation plan and the enablers, tactics, and key messages that allowed the hospital to move from one step to the next, thereby building the capacity for change. The ADKAR Model was eventuallly adopted as the hospital's official change management model and was taught to the managers and staff. 
Table 3. Houston Methodist Hospital (HMH) Texas Medical Center

\begin{tabular}{|c|c|c|}
\hline $\begin{array}{l}\text { ADKAR Model of } \\
\text { Change Management }\end{array}$ & Strategies & Key Tactics and Messages \\
\hline $\begin{array}{l}\text { Awareness of the need } \\
\text { for change }\end{array}$ & $\begin{array}{l}\text { Communicate vision for the } \\
\text { change and future state, } \\
\text { business reasons, scope, } \\
\text { timeline and seek input from } \\
\text { stakeholders }\end{array}$ & $\begin{array}{l}\text { - Two-way commutation vehicles: } \\
\text { - Board of Directors, department head, nursing leadership, service line and inter-professional } \\
\text { meetings } \\
\text { - Nursing leadership retreat/ meetings } \\
\text { - Staff nurse assemblies } \\
\text { - Emails } \\
\text { - Business reasons: } \\
\text { - Healthcare reform } \\
\text { - Pursuit of Magnet designation } \\
\text { - Competitive environment } \\
\text { - Timeline } \\
\text { - Shared governance literature distributed }\end{array}$ \\
\hline & $\begin{array}{l}\text { Highlight benefits of } \\
\text { implementing shared } \\
\text { governance }\end{array}$ & $\begin{array}{l}\text { - Design team facilitated monthly focus groups on each nursing unit and served as a resource for a year: } \\
\text { - Goal is to create an engaged workforce and superior outcomes } \\
\text { - Empowerment and decision-making at the point of service drives ownership of practice; enhances } \\
\text { collaboration; improves patient outcomes, morale, and nurse job satisfaction; lowers nurse vacancy } \\
\text { rate; and reduces costs }\end{array}$ \\
\hline & $\begin{array}{l}\text { Create career advancement and } \\
\text { compensation opportunities } \\
\text { (focus on "what's in it for } \\
\text { me?”) }\end{array}$ & $\begin{array}{l}\text { Key messages: } \\
\text { - Career ladder integration creates advancement opportunities and higher compensation for nurses } \\
\text { - Improved patient and staff outcomes yield higher compensation for nurses and managers } \\
\text { - Governance chairs selected in accordance with predetermined criteria earn career ladder } \\
\text { contribution points }\end{array}$ \\
\hline $\begin{array}{l}\text { Desire to participate \& } \\
\text { support the change }\end{array}$ & $\begin{array}{l}\text { Alleviate fear of role change } \\
\text { and job insecurity }\end{array}$ & $\begin{array}{l}\text { - Managers completed Birkman personality assessment and self- reflection exercise to assess their } \\
\text { knowledge, skills, prior experience, and readiness for change: } \\
\text { - Personal values } \\
\text { - Participative leadership style } \\
\text { - Communication/coaching style } \\
\text { - Shared governance competencies } \\
\text { - Systems thinking } \\
\text { - Role modeling } \\
\text { - Teamwork facilitation } \\
\text { - Experience as a change agent } \\
\text { - Strengths/opportunities/weaknesses (skills requiring further development) } \\
\text { - Key messages: } \\
\text { - No intent to eliminate jobs } \\
\text { - Concept of "shared decision-making" emphasized } \\
\text { - Trust and respect for managers fostered } \\
\text { DISC (Dominance, Influence, Consciousness, and Steadiness) Personality Style was administrated to } \\
\text { managers and staff as a mechanism to enhance relationships and teamwork }\end{array}$ \\
\hline \multirow[t]{2}{*}{$\begin{array}{l}\text { Knowledge on how to } \\
\text { change }\end{array}$} & $\begin{array}{l}\text { Identify shared governance } \\
\text { competencies for nursing } \\
\text { leaders and governance chairs } \\
\text { (focus on cognitive, analytical, } \\
\text { and behavioral changes) }\end{array}$ & $\begin{array}{l}\text { - Shared governance core competencies (for managers and staff unless otherwise specified) : } \\
\text { - ADKAR Model of Change Management } \\
\text { - Team facilitation (managers) } \\
\text { - Meeting facilitation } \\
\text { - Problem-solving } \\
\text { - Conflict management } \\
\text { - Decision-making } \\
\text { - Goal setting } \\
\text { - Performance Improvement (Plan-Do-Check-Act) } \\
\text { - Supplemental education: } \\
\text { - Coaching/ employee engagement (managers) } \\
\text { - Emotional Intelligence } \\
\text { - Crucial Conversations } \\
\text { - OZ Accountability Principle } \\
\text { - Lean Six Sigma White Belt Certification } \\
\text { - Evidenced-based practices (IOWA Model) } \\
\text { - Trust }\end{array}$ \\
\hline & $\begin{array}{l}\text { Determine impact on the role of } \\
\text { the staff }\end{array}$ & $\begin{array}{l}\text { - Managers assessed unit staff to identify implementation barriers: } \\
\text { - Formal versus informal leaders } \\
\text { - Group strengths and weaknesses } \\
\text { - Overall group dynamics, i.e., positive or negative, enthusiastic or hesitant } \\
\text { - Staff tenure, turnover, and vacancies } \\
\text { - Staff competencies } \\
\text { - Structure and processes for decision-making } \\
\text { - } \text { - Recognition and reward programs } \\
\text { - Managers assessed unit characteristics to identify barriers inhibiting change: } \\
\text { - Patient population } \\
\text { - Standards of care and practice } \\
\text { - Patient care delivery system: volume, length of stay, patient acuity, and technology } \\
\text { - Medical staff support } \\
\text { - Accessibility to ancillary departments }\end{array}$ \\
\hline
\end{tabular}


Table 3. (Continued.)

\begin{tabular}{|c|c|c|}
\hline $\begin{array}{l}\text { ADKAR Model of } \\
\text { Change Management }\end{array}$ & Strategies & Key Tactics and Messages \\
\hline \multirow[t]{2}{*}{$\begin{array}{l}\text { Knowledge on how to } \\
\text { change }\end{array}$} & $\begin{array}{l}\text { Educate on shared governance } \\
\text { principles and concepts }\end{array}$ & $\begin{array}{l}\text { - Shared governance principles: } \\
\text { - Partnerships-promote continuity of care and foster peer and inter-professional collaboration } \\
\text { - Accountability-staff own decisions, processes, self-governance/control, critical } \\
\text { reflection/synthesis, patient advocacy, and conflict management } \\
\text { - Shared decision-making—staff are empowered to make decisions that support their practice } \\
\text { - Shared governance key concepts: } \\
\text { - Unit structure should replicate house-wide councilor structure } \\
\text { - Decision-making drives responsibility, authority, and accountability } \\
\text { - Locus of control promotes decisions related to practice issues, such as care delivery system, } \\
\text { staffing requirements, quality assurance, evidenced-based performance improvement, } \\
\text { professional development, resource management, recruitment and retention, and work redesign } \\
\text { - Shared governance roles, responsibilities, professional attributes, and unit performance factors } \\
\text { - Shared governance conference with nursing leaders and governance chairs featured Tim Porter } \\
\text { O’Grady } \\
\text { - Two-day workshops (ongoing) sponsored by the design team, Organizational Development, } \\
\text { and the Workplace Environment Council } \\
\text { - Presentations on Plan-Do-Check-Act for managers and governance chairs } \\
\text { - Annual conference with governance chairs features motivational speaker and an organizational } \\
\text { priority } \\
\text { - Shared governance concepts and structure integrated into new employee orientation } \\
\text { - Requirement for shared governance participation integrated into competency-based pre-hire } \\
\text { interviewing tool }\end{array}$ \\
\hline & Provide access to information & $\begin{array}{l}\text { - Shared governance implementation checklist and monthly calendar detailing milestones } \\
\text { distributed } \\
\text { - Department of Nursing Operations established to house all nursing quality, productivity, and } \\
\text { financial data } \\
\text { - Council goals linked with nursing Dashboard metrics } \\
\text { - Nursing Dashboard posted on HMH's intranet for easy access by governance councils to metrics } \\
\text { and outcomes } \\
\text { - A shared governance intranet site and tool kit was constructed; hard copy distributed to each } \\
\text { nursing unit } \\
\text { - A "how to" shared governance manual and CD ROM was authored by HMH-staff, introduced at } \\
\text { educational forums, and distributed to each nursing unit (2008) }\end{array}$ \\
\hline $\begin{array}{l}\text { Reinforcement to } \\
\text { sustain the change }\end{array}$ & $\begin{array}{l}\text { Sustain change through } \\
\text { employee incentive program }\end{array}$ & $\begin{array}{l}\text { - Service line shared governance showcases presented by unit councils } \\
\text { - Best practices presentations at governance assemblies } \\
\text { - Opportunities offered three times a year to present best practices posters with the potential to win a } \\
\text { prize } \\
\text { - Best practices stories publicized in nursing and Magnet champion newsletters and at shared } \\
\text { - } \text { Novernance and Magnet champion meetings } \\
\text { - staff) and merit increases } \\
\text { - Shared governance outcomes routinely evaluated through nursing Dashboard outcomes, validated } \\
\text { staff satisfaction surveys, and periodic assessment of each unit's governance structure, processes, } \\
\text { articulation of council goals, and outcomes. } \\
\text { - Ongoing shared governance education (new employee orientation, Nursing Leadership Orientation } \\
\text { Program to introduce managers to HMH's standards, governance structure, processes, and } \\
\text { expectations followed by individual meetings with managers. Shared Governance Leadership } \\
\text { Series (8-hour workshops) and refresher sessions held with governance chairs. Lean Six Sigma } \\
\text { regularly scheduled). }\end{array}$ \\
\hline
\end{tabular}

\subsection{Awareness}

Numerous leadership meetings were held to communicate the vision and desired future state for implementing shared governance, the business reasons and benefits, the scope of change, and the timeline. These meetings were useful in seeking input from key stakeholders on potential obstacles, concerns, and questions pertaining to the change and the proposed timeline. To prepare for the wave of activities that were to be unleashed, the design team distributed shared governance literature and hosted a retreat with nursing leaders to formally launch the implementation plan. As the 
implementation phase got underway, announcements were made at leadership meetings, at staff nurse assemblies, and through email blasts.

\subsection{Desire}

There were numerous opportunities to continue to highlight and reinforce the benefits of a shared governance environment. The governance coach assigned to each unit was instrumental in introducing and hosting discussions with unit staff regarding the benefits of shared governance. An important consideration in promoting buy-in was to emphasize, "What's in it for me?" The answer was that shared governance allows nurses to exercise independent judgment, make decisions about how they deliver care, and gives them control over their practice, which contributes to greater job satisfaction and nurse retention, while also enhancing collaboration and improving patient outcomes. These preliminary discussions were used to solicit concerns and clarify misconceptions, for example, the types of decisions made in a "shared governance" environment, while also reassuring the managers that there was no intent to eliminate jobs and that this change should be viewed as an opportunity to create greater trust and respect for the managers. To incentivize staff participation, gradations of shared governance participation were built into the nurses' job descriptions and career ladder, offering the opportunity for advancement and potentially additional compensation. The managers were rewarded as their unit outcomes improved.

Key roles of nursing leaders during the integration cycle were that of system thinker, change agent, educator, coach, facilitator, and servant leader. These roles required that managers have insight into their own personality traits, their readiness for change, and how they approached the work at hand. The Birkman Method and Dominance, Influence, Conscientiousness, and Steadiness (DISC) personality type assessments were routinely administered to nursing leaders as change agents to help bridge this gap. Also, a self-reflection exercise was used to assess the nursing leaders' knowledge, skills, values, and experience. The DISC was also administered to the nursing staff. The Birkman provides insight into an individual's needs, stress behaviors, and strengths that impact individual and team effectiveness ${ }^{[21]}$. The DISC enhances self-knowledge and reveals how an individual will respond to conflict and stress and solve problems. This knowledge enhances an individual's ability to adapt to others and engage in constructive interactions and promotes better teamwork $^{[22]}$.

\subsection{Knowledge}

Competencies form the foundation for performance and set the standards for success that support an organization's vision, mission, strategies, and goals. Carroll and McCrackin ${ }^{[23]}$ defined competencies as the "knowledge, skills, capabilities, attitudes, or behaviors that characterize excellent performance within a specific context.” Shared governance competencies, such as meeting facilitation, problem-solving, conflict management, decision-making, goal setting, and performance improvement were identified as essential for nursing leaders and governance chairs. Hess ${ }^{[24]}$ reinforced the need for managers and staff to be educated on management skills, such as delegation and meeting participation and facilitation prior to implementing shared governance.

Leading change effectively required that the managers have an in-depth understanding of governance principles and concepts and proficiency in change management, coaching, team building, communicating, and visibly navigating the desired change. Initially, education focused on three key areas: shared governance principles, concepts, and competencies, which were essential in transforming and functioning in the new environment ${ }^{[25]}$. Education of nursing leaders was prioritized as leaders set the stage and would ultimately influence the success of this critical mission change. It was imperative that the leadership team understood and accepted the reasons for shifting to an accountability-based professional practice model and their role in this endeavor, because they were tasked with reinforcing the vision and goals for implementing shared governance, completing a gap analysis that assessed their own abilities and those of their staff and unit, and constructing a detailed, unit-specific, step-by-step implementation roadmap. The roadmap identified group leaders, education and communication plans, program evaluation metrics, reporting structure, and the incentive program. Managers were given a final implementation checklist and a monthly calendar (see Table 4) that outlined milestones and completion dates. Individual unit roadmaps were approved by the service line executive and design team. 
Table 4. Houston Methodist Unit Shared Governance Implementation Calendar (2000)

\begin{tabular}{|c|c|c|c|}
\hline January & February & March & April \\
\hline $\begin{array}{l}\text { Design team identifies scope } \\
\text { of change, plan, resources and } \\
\text { competencies }\end{array}$ & $\begin{array}{l}\text { Shared governance baseline } \\
\text { survey administered to nurses } \\
\text { Shared governance literature } \\
\text { distributed to directors }\end{array}$ & $\begin{array}{l}\text { Nursing Leadership Retreat: } \\
\text { - Vision } \\
\text { - Shared governance education } \\
\text { - Toolkit distributed } \\
\text { - Roadmap, gap analysis, and } \\
\text { timeline reviewed }\end{array}$ & $\begin{array}{l}\text { Managers complete gap } \\
\text { analysis: self, staff, and unit } \\
\text { Managers draft roadmap } \\
\text { (transition plan) } \\
\text { Manager shared governance } \\
\text { competency education } \\
\text { initiated }\end{array}$ \\
\hline May & June & July & August \\
\hline $\begin{array}{l}\text { House-wide shared } \\
\text { governance education } \\
\text { Design team holds unit focus } \\
\text { groups } \\
\text { Roadmaps approved by } \\
\text { service line executive and } \\
\text { design team } \\
\text { Manager shared governance } \\
\text { competency education } \\
\text { continues }\end{array}$ & $\begin{array}{l}\text { House-wide shared governance } \\
\text { education } \\
\text { Design team holds unit focus } \\
\text { groups } \\
\text { Roadmap implemented } \\
\text { DISC administered to staff } \\
\text { Shared governance chair } \\
\text { competency education initiated }\end{array}$ & $\begin{array}{l}\text { House-wide shared governance } \\
\text { education } \\
\text { Design team attends council } \\
\text { meetings as facilitators } \\
\text { Unit shared governance model } \\
\text { implemented } \\
\text {-council charter drafted } \\
\text { Shared governance chair } \\
\text { competency education } \\
\text { continues }\end{array}$ & $\begin{array}{l}\text { Nursing Leadership Retreat } \\
\text { Design team attends council } \\
\text { meetings as facilitators }\end{array}$ \\
\hline September & October & November & December \\
\hline $\begin{array}{l}\text { Design team assesses unit } \\
\text { compliance } \\
\text { Outcomes evaluated } \\
\text { Executive summary prepared }\end{array}$ & $\begin{array}{l}\text { Design team regroups, develops } \\
\text { and implements action plan to } \\
\text { address learning needs }\end{array}$ & $\begin{array}{l}\text { Reinforcement/ Ongoing } \\
\text { Support }\end{array}$ & $\begin{array}{l}\text { Reinforcement/ Ongoing } \\
\text { Support }\end{array}$ \\
\hline
\end{tabular}

The managers scheduled numerous staff meetings to share their vision and build the case for implementing shared governance. These discussions centered on nursing's vision with an emphasis on the core business of providing excellent patient care, while optimizing staff satisfaction and the vehicle for achieving this vision, i.e., shared governance. The staff on each shift were involved in group activities to assess the unit's characteristics and the needs of patients and staff, as well as potential barriers (see Table 2). Information gathered from these sessions identified learning needs and opportunities for improvement that guided individual unit roadmaps. Shared governance principles and concepts and the related skills, roles, responsibilities, attributes of professional practice, and unit performance factors that a governance model should drive were introduced during these meetings. These discussions were supplemented by a 2-day workshop for managers and governance chairs and additional periodic education sponsored by the design team, Organizational Development and Workplace Environment Council, that spanned beyond the initial implementation period. This included annual governance conferences featuring keynote speakers, such as Tim Porter-O’Grady, and more in-depth education on performance improvement methodologies. Such education included Plan-Do-Check-Act and Lean Six Sigma White Belt Certification in addition to evidenced-based practices (IOWA Model). As the governance model evolved, it was determined that other classes were needed that facilitated engagement and relationship building. Managers were offered education on coaching, and classes on Emotional Intelligence, Crucial Conversations, the Oz Accountability Principle, and trust were made available to the managers and staff at large.

To facilitate governance activities, the design team developed a shared governance toolkit that included guidelines for implementing the role of a governance chair, facilitating meetings, establishing ground rules, improving performance by using "Plan, Do, Check, Act," and engaging employees. The toolkit also contained articles, PowerPoint presentations, numerous templates, and sample documents. The sample documents included a council charter, roster, agenda, minutes, blueprint for SMART (S-Specific, M-Measurable, A-Agreed, R-Realistic, T-Time-framed) goals, calendar for reporting outcomes, chair competency-based evaluation, and a pre-hire behavioral interviewing tool that addressed the requirement for shared governance participation. In 2008, a shared governance manual (178 pages) and CD ROM authored by HMH staff were distributed to each nursing unit as an additional resource for the managers and staff. 


\subsection{Ability}

Each nursing unit was supported by a member of the design team, who served as a consultant and coach to the managers and staff. The consultant helped to guide the development of the governance structure of the unit to mirror the house-wide structure (practice, quality, education, and evidenced-based practice) and the processes that support the structure. Within a shared governance framework, the staff were given the opportunity to further delineate these logistics, which included their monthly meeting schedule, ground rules, duties and responsibilities, goals linked to Dashboard outcomes, two-way communication vehicles, decision-making process (i.e., by consensus, quorum, or majority rules), and schedule for providing updates and seeking input from the staff at large.

Once the council chairs were selected, 7 to 10 members per council were recruited. Seventy percent of the members were nurses and the others were patient care assistants, unit secretaries, and other staff working on a unit. The manager and coach on each unit met with these groups to reinforce the expectation that the council's goals be aligned with the unit's departmental goals, in addition to addressing opportunities related to the practice environment. The Nursing Dashboard includes human resources, clinical quality, service quality, and financial outcome data. The managers provided Dashboard outcome data to the chairs to share at the first council meeting to help the council formulate its goals. An agenda was jointly prepared. During the initial meetings, a council charter was drafted that outlined the council's purpose, membership, meeting schedule, goals, member duties, ground rules, and attendance requirements. All council members signed the charter to convey their commitment to its success. The design team member on each unit worked with each council to help them refine and establish SMART goals, data sources, and a reporting schedule. A 12-month meeting schedule was posted on a bulletin board to promote attendance along with each council’s goals.

The manager and coach attended the initial meetings as facilitators and change agents. Eventually, the chairs assumed responsibility for preparing the agendas and reviewing these with their managers in advance of each meeting. This gave the managers the opportunity to provide input without having to attend a meeting, which is ideal in a shared governance environment where the goal is to build leadership capacity, autonomy, control, and ownership of practice. Following each meeting, the chairs debriefed with their manager as a way of keeping them informed and fostering support for initiatives. Meeting minutes were recorded and posted. The chairs were scheduled to give an update at monthly staff meetings and used this opportunity to seek input on proposed actions, while obtaining help with these tasks.

Although a member of the design team worked closely with each nursing unit, encouraging staff to remain focused, listening to their concerns, and monitoring their progress, the manager's role in reshaping the culture was vital. Before the staff would accept the implementation of a governance model, the managers first had to demonstrate their acceptance and enthusiasm in leading this charge. They were instrumental in clarifying role expectations, facilitating the selection of council chairs and members in accordance with pre-established criteria, allocating time for the staff to attend governance meetings and complete project work, providing the framework and empowering the staff to make decisions, coaching them, eliminating barriers, and recognizing individual and group accomplishments.

Midway through the implementation phase, a second retreat was held to create a forum for the managers to exchange experiences and to share what had worked and what had not. Following the retreat, the managers facilitated attendance of their staff at governance meetings on best practices units. These observations on model units instilled confidence in the staff's ability to replicate the structure and processes on their own unit.

Three months after implementation, the design team completed a comprehensive assessment of each unit's governance model. An executive summary was reviewed with the unit manager and service line executive to facilitate additional reinforcement and trouble shooting. In addition to the design team, the Magnet Program director and organizational development consultants were available to help the staff solve problems. The Department of Nursing Operations was established to house all nursing quality, productivity, and financial data and to maintain a repository on nursing's intranet for quick access by governance councils. 


\subsection{Reinforcement}

As the implementation phase progressed, ongoing and frequent communication, acknowledgement, and dissemination of small accomplishments and best practices became an important strategy in reinforcing the work at hand. Avenues such as best practices presentations at governance meetings and email dissemination were initially identified to publicize the work being done by unit councils. Over time, these forums were expanded to include service line showcases by unit councils, presentations at governance assemblies, poster presentations several times a year, and stories in nursing's newsletters. Recognizing and visibly showing appreciation for the staff's contributions built enthusiasm and commitment. Dashboard outcomes were eventually integrated as a component of annual performance reviews and linked to merit increases to promote ongoing focus and ownership of these outcomes.

Other strategies aimed at sustaining the gains made in implementing a shared governance model included the following:

- $\quad$ Ongoing quarterly inter-professional pillar huddles facilitated by Nursing Operations on each unit with governance chairs and managers to review Dashboard outcomes and action plans;

- $\quad$ Periodic assessment of each unit's governance structure and council meeting schedule, chairs, and goals; and

- Staff interviews on each unit to assess their knowledge and ability to articulate their governance structure, Dashboard outcomes, opportunities, and action plans.

All managers and staff are offered shared governance education as a component of new employee orientation. In addition to these strategies, numerous educational forums are sponsored on an ongoing basis. For example, new managers attend a Nursing Leadership Orientation Program, which addresses shared governance followed by individual meetings with new managers to reinforce the hospital's shared governance standards, structure, processes, and expectations. The Workplace Environment Council sponsors a Shared Governance Leadership Series for governance chairs consisting of 8-hour workshops that span several months. These efforts are supplemented by Nursing Operations, which periodically hosts refresher training sessions with governance chairs and Magnet champions and also utilizes these groups in an advisory capacity when rolling out new initiatives that impact the Dashboard data. Lean Six Sigma classes are also offered regularly. Additionally, a 4-hour Manager Shared Governance Boot Camp was held this year that targeted a cadre of new managers.

\section{Outcomes}

The goal for implementing unit-level governance was to build a high-performing clinical setting that yielded superior patient and staff outcomes and thus supported nursing's strategic priorities. The hospital's adopted patient care delivery system (Patient and Family Centered Care) and the desired outcomes associated with this system guided the work and actions of the units and the organization as a whole. By remaining focused on the three guiding principles that support Patient and Family Centered Care (staff nurse leadership, inter-professional team, and communication/collaboration with the patient and family), clinical and service quality outcomes improved as each contributor strengthened within the model (see Table 5).

The change in management's leadership style from one of control to one of engagement, facilitation, and coaching positively impacted the way that bedside nurses practiced. As the nurses became more involved in making decisions pertaining to patient care activities and other unit initiatives, nurse satisfaction with autonomy, decision-making, professional status, and professional development also improved (see Table 5). As staff were given the opportunity to apply their knowledge and develop mastery, the chairs exerted greater leadership and ownership in convening and coordinating the work of their council. For example, the chairs sent out reminder meeting notices and minutes detailing assignments, generated the agendas, pulled Dashboard outcomes from the nursing intranet to review at council meetings, collaborated with council members to drive action plans, and summarized and reported the work of the council at monthly staff meetings. To keep the staff engaged, council chairs came up with creative ideas to start each meeting. These included ice breakers, refreshments, and other team building activities. Governance chairs also worked with their managers to 
recognize and celebrate the council's accomplishments. Recognizing and rewarding the staff for even small accomplishments was an important factor in promoting enthusiasm and engagement. Over time, as the culture started to shift, the staff began to identify opportunities for improvement and to inform managers of the problems and the solutions they were exploring, rather than the managers identifying and bringing these to their attention. As opportunities were identified, the staff volunteered to conduct literature searches and lead a subgroup to address these. This signaled the formation of new norms that conveyed an understanding of the value that shared governance plays in relinquishing the decision-making control to bedside clinicians and the reciprocal expectation that these clinicians be accountable for these outcomes. Today, shared governance has progressed to the point that some nursing units have family members participate on their governance councils.

Table 5. Houston methodist nurse and patient outcomes

\begin{tabular}{|c|c|c|c|}
\hline & $\begin{array}{l}\text { Pre-Implementation } \\
2000\end{array}$ & $\begin{array}{l}\text { Early Implementation } \\
2004\end{array}$ & $\begin{array}{l}\text { Implemented } \\
2012\end{array}$ \\
\hline \multicolumn{4}{|l|}{ Human Resource Outcomes } \\
\hline RN Turnover & No data & $12.23 \%$ & $9.46 \%$ \\
\hline Direct Care Hours Per Patient Day & 7.35 & 9.2 & 10.4 \\
\hline \multicolumn{4}{|l|}{ NDNQI RN Satisfaction } \\
\hline (Scale: & $\begin{array}{l}<40 \text { - low satisfaction, } \\
\text { No data }\end{array}$ & $\begin{array}{l}\text { 40-60 moderate satisfaction, } \\
53.46\end{array}$ & $\begin{array}{l}>60 \text { high satisfaction) } \\
57.16\end{array}$ \\
\hline Decision-Making & No data & 52.51 & 55.51 \\
\hline Professional Status & No data & 70.45 & 73.68 \\
\hline Professional Development & No data & 64.36 & 68.57 \\
\hline \multicolumn{4}{|l|}{ Clinical Outcomes } \\
\hline Patient Falls per 1,000 Patient Days & 2.80 & 2.70 & 2.25 \\
\hline Hospital-Acquired Pressure Ulcer & $6.75 \%$ & $5.42 \%$ & $1.82 \%$ \\
\hline \multicolumn{4}{|c|}{$\begin{array}{l}\text { Patient Satisfaction (Note: Survey instrument changed in } 2007 \text { from a phone survey with a response of "yes, definitely" or "very } \\
\text { good/excellent" to a converted five-point Likert scale mean score, with ranges of "very poor" to "very good," gathered from mailed } \\
\text { surveys) }\end{array}$} \\
\hline & & 2007 & \\
\hline Overall Experience & $80.8 \%$ & $86.2 \%$ & 88.6 \\
\hline Overall Nursing Services & $82.9 \%$ & No data & 90.7 \\
\hline With Pain Management & $86.9 \%$ & $86.8 \%$ & 88.8 \\
\hline
\end{tabular}

Note. NDNQI RN survey: National Database of Nursing Quality Registered Nurse survey.

Progression of the governance model was evaluated through annual National Database of Nursing Quality (NDNQI) Registered Nurse surveys that measure satisfaction with autonomy, decision-making, professional status, and professional development. Visits with individual units facilitated assessment of the structure, processes, and knowledge of goals and Dashboard outcomes. During the summer of 2013, a repeat shared governance survey was administered during regularly scheduled meetings with Magnet champions, shared governance chairs, and members of the Professional Nurse Advisory Council, who represented a cross-section of nursing units. This instrument included the same variables as the first survey but was expanded beyond the initial focus and validated by content experts. Surveys were administered to 72 nurses present in these meetings; 59 nurses (82\% of this population) responded to the survey. The results (see Table 6) reflected favorable progress in each of the baseline variables previously studied; however, the percentage of nurses who had knowledge of how to form a council was lower than expected. During 2013, the hospital hired an influx of new managers and nurses, which may have influenced this response rate.

Table 6. Shared governance post-implementation survey results: percentage of nurses who responded "Yes" (2013)

\begin{tabular}{ll}
\hline Survey Question & Percentage \\
\hline Staff buy-in/ownership & $100 \%$ \\
Structure for shared decision-making (shared governance) in place & $100 \%$ \\
Knowledge of shared governance role & $91 \%$ \\
Knowledge of how to form a council & $68 \%$ \\
\hline
\end{tabular}


Manager flexibility enabled the staff to achieve better outcomes and was characterized by a conscious effort to relinquish control and promote staff autonomy to allow the staff to do their best work. Optimizing performance involved a fierce determination to provide feedback to staff on a consistent basis. In order for the staff to master their craft, feedback must come from leadership, and often. If the staff do not know how they are doing, they won't know how to improve. Leaders also have to create an avenue for the staff to give each other feedback.

Manager flexibility also involved a willingness to communicate in the manner in which the staff wanted to receive communication. Nursing spans a broad generational spectrum. Being aware of how each generation gives and receives communication will enhance the leader’s effectiveness in transferring information.

Taking time to play together as a team is also important. Celebrating successes and providing an environment that fosters creativity may lead to innovation. Saying "thank you” and recognizing other's efforts is a powerful strategy for engaging staff, because they are acutely aware when the leader has their best interests at heart.

\section{Conclusion}

Today more than ever before, a strong shared governance culture is essential in meeting the demands of an ever-changing health care environment driven by increasing regulations, shrinking resources, and increasing workloads. As an organization transitions from a traditional hierarchical structure to one of collaborative partnerships and shared decision-making, it is essential that key stakeholders, particularly the leadership team, understand the implications and value of a governance model, both at the organizational level and the individual level. Changing a culture to one that decentralizes decisions and empowers clinicians at the point of service to determine the structures, processes, and standards essential to the delivery of patient care requires not only new knowledge, skills, and behaviors but also unrelenting leadership support, modeling, and investment of time and energy. The ADKAR Change Management Model provides a framework for any change initiative and has served this organization well in implementing shared governance. Shared governance models are dynamic and evolve over time, and as such, require ongoing monitoring, education, and coaching.

\section{References}

[1] Buerhaus PB, DesRoches C, Applebaum S, Hess R, Norman LD, Donelan K. Are nurses ready for health care reform? A Decade of Survey Research. Nurs Econ. 2012; 30(6): 318-29. PMid:23346730

[2] American Nurses Credentialing Center. 2014 Magnet Application Manual. Silver Spring (MD): American Nurses Credentialing Center; 2013.

[3] Watters S. Shared leadership: taking flight. J Nurs Adm. 2009; 39(1): 26-9. PMid:19104284 http://dx.doi.org/10.1097/NNA.0b013e31818fe7a8

[4] Weston MJ. Strategies for enhancing autonomy and control over nursing practice. Online J Issues Nurs. 2010; 15(1). Available from:

http://www.nursingworld.org/MainMenuCategories/ANAMarketplace/ANAPeriodicals/OJIN/TableofContents/Vol152010/No1 Jan2010/Enhancing-Autonomy-and-Control-and-Practice.html.

[5] Porter-O’Grady T. Researching shared governance: a futility of focus. J Nurs Adm. 2003; 33(4): 251-2. PMid:12690257 http://dx.doi.org/10.1097/00005110-200304000-00011

[6] Kramer M, Schmalenberg C, Maguire P, Brewer BB, Burke R, Chmielewski L, et al. Structures and practices enabling staff nurses to control their practice. West J Nurs Res. 2008; 30(5): 539-59. PMid:18195080 http://dx.doi.org/10.1177/0193945907310559

[7] Weston MJ. Antecedents of Control over Nursing Practice [dissertation]. [Tucson (AZ)]: University of Arizona; 2006. Available from: https://www.nursing.arizona.edu/Library/Weston_M.pdf.

[8] Skar R. The meaning of autonomy in nursing practice. J Clin Nurs. 2009; 19: 2226-34. PMid:19538554

[9] Muñiz Castillo MR. Autonomy as a foundation for human development: a Conceptual Model to Study Individual Autonomy [working paper]. (Maastricht, The Netherlands): Maastricht Graduate School of Governance; 2009.

[10] Dworkin G. The theory and practice of autonomy. Cambridge (United Kingdom): Cambridge University Press; 1988. 
[11] McParland J, Scott PA, Arndt M, Dassen T, Gasull M, Lemonidou C, et al. Autonomy and clinical practice 1: identifying areas of concern. Br J Nurs. 2000; 9: 507-13.

[12] Barden AM, Griffin RN, Donahue M, Fitzpatrick JJ. Shared governance and empowerment in registered nurses working in a hospital setting. Nurs Adm Q. 2011; 35(3): 212-8. PMid:21654480 http://dx.doi.org/10.1097/NAQ.0b013e3181ff3845

[13] Kanter RM. Men and women of the corporation. New York (NY): Basic Books; 1977.

[14] Pink DH. Drive: the surprising truth about what motivates us. New York (NY): Riverhead Books; 2009.

[15] Weston MJ. Defining control over nursing practice and autonomy. J Nurs Adm. 2008; 38(9):404-8. PMid:18791425 http://dx.doi.org/10.1097/01.NNA.0000323960.29544.e5

[16] Dweck C. Mindset: the new psychology success. New York (NY): Random House; 2006.

[17] Hooper A, Potter J. Intelligent leadership: creating a passion for change. London (United Kingdom): Random House; 2000.

[18] Porter-O’Grady T. Unit-based shared governance activities. Chapter 6. In: Shared Governance Implementation Manual [Internet]. Atlanta (GA): Tim Porter-O’Grady Associates; 1992. Available from: http://www.tpogassociates.com/sharedgovernance/chapter6.pdf.

[19] Walker J. Developing a shared leadership model at the unit level. J Perinat Neonatal Nurs. 2001; 15(1): 26-39. PMid:12095005 http://dx.doi.org/10.1097/00005237-200106000-00005

[20] Hiatt JM. ADKAR: a model for change in business, government and our community. Loveland (CO): Prosci Research; 2006.

[21] Wadlington PL. A Comparison between the Birkman Method and the Hogan Personality Inventory [Internet]. Birkman International; 2012. Available from: http://d1p3wm1hneu8o1.cloudfront.net/TBM_HPI\%20(final)\%20120204.pdf.

[22] Bradley A. Everything DISC workplace [Internet]. St. Petersburg (FL): Your Life’s Path; 2012. Available from: http://www.yourlifespath.com/data/shopcart7/content_db/Sample_Everything_DiSC_WorkplaceAT_Report.pdf.

[23] Carroll A, McCrackin J. The competent use of competency-based strategies for selection and development. Performance Improvement Quarterly. 1998; 11(3):45-63. http://dx.doi.org/10.1111/j.1937-8327.1998.tb00099.x

[24] Hess R. From bedside to boardroom-nursing shared governance. Online J Issues Nurs. 2004; 9(1). Available from: http://www.nursingworld.org/MainMenuCategories/ANAMarketplace/ANAPeriodicals/OJIN/TableofContents/Volume92004/N o1Jan04/FromBedsidetoBoardroom.html. PMid:14998346

[25] Smith S, Porter-O'Grady T. Nursing staff roles in unfolding shared governance. Chapter 5. In: Implementing Shared Governance: Creating a Professional Organization [Internet]. Atlanta (GA): Tim Porter-O’Grady Associates; 1992:111-125. Available from: http://www.tpogassociates.com/sharedgov-book/Chapter5/PDF-5.pdf 